\title{
SpringerReference
}

PhD Richard Bertram

Department of Mathematics, Florida State University, Tallahassee, USA

Arthur Sherman

Laboratory of Biological Modeling, Bethesda, USA

Leslie S. Satin

Department of Pharmacology and Brehm Diabetes Center, Ann Arbor, USA

Editor

Md. Shahidul Islam, M.D., Ph.D. Department of Clinical Sciences and Education, Södersjukhuset, Stockholm, Sweden

\section{Electrical, Calcium, and Metabolic Oscillations in Pancreatic Islets} Islets of Langerhans · Article ID: 366965 - Chapter ID: 10

\section{[edit] [options]ABSTRACT}

Oscillations are an integral part of insulin secretion, and are due ultimately to oscillations in the electrical activity of pancreatic $\beta$-cells, called bursting. We discuss the underlying mechanisms for bursting oscillations in mouse islets and the parallel oscillations in intracellular calcium and metabolism. We present a unified biophysical model, called the Dual Oscillator Model, in which fast electrical oscillations are due to the feedback of $\mathrm{Ca}^{2+}$ onto $\mathrm{K}^{+}$ion channels, and the slow component is due to oscillations in glycolysis. The combination of these mechanisms can produce the wide variety of bursting and $\mathrm{Ca}^{2+}$ oscillations observed in islets, including fast, slow, compound, and accordion bursting. We close with a description of recent experimental studies that have tested unintuitive predictions of the model and have thereby provided the best evidence to date that oscillations in glycolysis underlie the slow ( $5 \mathrm{~min})$ component of electrical, calcium, and metabolic oscillations in mouse islets.

Keywords: bursting, insulin secretion, islet, pulsatility, oscillations

Like many neurons and endocrine cells, pancreatic $\beta$-cells are electrically excitable, producing electrical impulses in response to elevations in glucose. The electrical spiking pattern typically comes in the form of bursting, and is most well studied in mouse islets. Bursting is characterized as periodic clusters of impulses followed by silent phases when there is a cessation of impulse firing (Fig. 1). In this chapter we discuss the different types of bursting patterns observed in mouse islets and the underlying mechanisms for these oscillations and parallel oscillations in intracellular $\mathrm{Ca}^{2+}$ and metabolism.
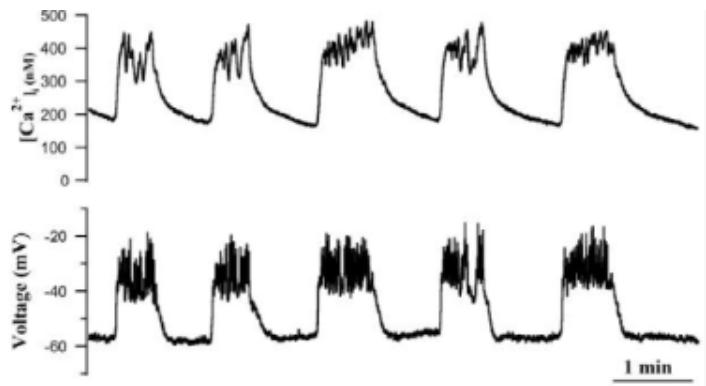

Figure 1: Intracellular free $\mathrm{Ca}^{2+}$ concentration measured using fura-2/AM (top) and electrical bursting (bottom) recorded from a mouse islet. Reprinted from Zhang et al. (2003).

Bursting electrical activity is important since it leads to oscillations in the intracellular free $\mathrm{Ca}^{2+}$ concentration (Santos et al. 1991; Beauvois et al. 2006), which in turn lead to oscillations in insulin secretion (Gilon et al. 1993). Oscillatory insulin levels have been measured in vivo (Lang et al. 1981; Pørksen et al. 1995; Pørksen 2002; Nunemaker et al. 2005), and sampling from the hepatic portal vein in rats, dogs, and humans shows large oscillations with period of 4 to 5 min (Song et al. 2000; Matveyenko et al. 2008). Deconvolution analysis demonstrates that the oscillatory insulin level is due to oscillatory secretion of insulin from islets (Pørksen et al. 1997; Matveyenko et al. 2008), and in humans at least $75 \%$ of insulin secretion is in the form of insulin pulses (Pørksen et al. 1997). The amplitude of insulin oscillations in the peripheral blood of human subjects is $\sim 100$ times smaller than in the hepatic portal vein (Song et al. 2000). This attenuation is confirmed by findings of hepatic insulin clearance of $\sim 50 \%$ in dogs (Polonsky et al. 1983), and $\sim 40-80 \%$ in humans (Eaton et al. 1983; Meier et al. 2005). It has also been demonstrated that the hepatic insulin clearance rate itself is oscillatory, corresponding to portal insulin oscillations. That is, during the peak of an insulin oscillation the insulin clearance rate is greater than during the trough (Meier et al. 2005). This illustrates that insulin oscillations are treated differently by the liver than non-pulsatile insulin levels, and thus suggests an important role for oscillations in the hepatic processing of insulin and, presumably, of glucose. Additional supporting evidence for this is provided by a study showing that glucose clearance is facilitated when insulin is pulsatile (Matveyenko et al. 2012). Clinical evidence for the importance of pulsatile insulin comes from studies showing that coherent insulin oscillations are disturbed or lost in patients with type II diabetes and their near relatives (Matthews et al. 1983; Weigle 1987; O'Rahilly et al. 1988; Polonsky et al. 1988).

Oscillations in insulin have also been observed in the perifused pancreas (Stagner et al. 1980), and in isolated islets (Longo et al. 1991; Bergsten and Hellman 1993; Gilon et al. 1993; Beauvois et al. 2006; Ritzel et al. 2006). The oscillations have two distinct periods; the faster oscillations have a period of 2 min or less (Gilon et al. 1993; Bergsten 1995; Bergsten 1998; Nunemaker et al. 2005) while the slower oscillations have greater periods of often 4 min or more (Pørksen et al. 1995; Pørksen 2002; Nunemaker 
et al. 2005). In one recent study, insulin measurements were made in vivo in mice, and it was shown that some mice had insulin oscillations with period of 1-2 min ("fast mice"), while others exhibited a greater period of 3-5 min ("slow mice"). Interestingly, most of the islets examined in vitro from a given mouse had $\mathrm{Ca}^{2+}$ oscillations with similar periods. Most islets from "fast mice" had fast $\mathrm{Ca}^{2+}$ oscillations, while most of those examined from "slow mice" exhibited either slow or compound $\mathrm{Ca}^{2+}$ oscillations (fast oscillations superimposed on slow ones). Thus, it was conjectured that islets within a single animal are imprinted with a relatively uniform oscillation period that is reflected in the insulin profile in vivo. As we describe later, the two time scales of electrical bursting can explain the two components of oscillatory insulin secretion and their combinations.

\section{THE ROLE OF CALCIUM FEEDBACK}

$\mathrm{Ca}^{2+}$ enters $\beta$-cells through $\mathrm{Ca}^{2+}$ channels during the active phase of a burst, during which it

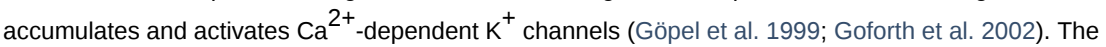
resulting hyperpolarizing current is in many cases sufficient to terminate the active phase of the burst, and the time required to deactivate the current can set the duration of the silent phase of the burst (Chay and Keizer 1983). Indeed, the first mathematical model for bursting in $\beta$-cells was based on this mechanism (Chay and Keizer 1983). The endoplasmic reticulum (ER) plays a major role in shaping the $\mathrm{Ca}^{2+}$ dynamics, taking up $\mathrm{Ca}^{2+}$ during the active phase of a burst (using the sarco- endoplasmic reticulum $\mathrm{Ca}^{2+}$ ATPase or SERCA pump; (Ravier et al. 2011)) when $\mathrm{Ca}^{2+}$ influx into the cytosolic compartment is large and releasing $\mathrm{Ca}^{2+}$ during the silent phase of the burst. These filtering actions have a significant impact on the time dynamics of the cytosolic $\mathrm{Ca}^{2+}$ concentration, and on the period of bursting. The influence of the ER on cytosolic free $\mathrm{Ca}^{2+}$ dynamics was convincingly demonstrated using pulses of $\mathrm{KCl}$ to effectively voltage clamp the entire islet (Gilon et al. 1999; Arredouani et al. 2002). Using 30-sec pulses, similar to the duration of a fast burst, it was shown that the amplitude of the $\mathrm{Ca}^{2+}$ response to depolarization was greater when the ER was drained of $\mathrm{Ca}^{2+}$ by pharmacologically blocking $\mathrm{ER} \mathrm{Ca}^{2+}$ pumps (SERCA). In addition, the slow decline of the cytosolic $\mathrm{Ca}^{2+}$ concentration that followed the more rapid declining phase of cytosolic $\mathrm{Ca}^{2+}$ was absent when SERCA pumps were blocked. The mechanisms for these effects were determined in mathematical modeling studies (Bertram and Sherman 2004; Bertram and Arceo II 2008), and it was demonstrated that an active form of $\mathrm{Ca}^{2+}$-induced $\mathrm{Ca}^{2+}$ release (CICR) is inconsistent with data from (Gilon et al. 1999; Arredouani et al. 2002). CICR did occur in single $\beta$-cells in response to cyclic AMP (Ämmälä et al. 1993), but in this case electrical activity and $\mathrm{Ca}^{2+}$ oscillations are out of phase (Keizer and De Young 1993; Zhan et al. 2008), which contrasts with the in-phase oscillations observed in glucose-stimulated islets (Santos et al. 1991; Beauvois et al. 2006). These predictions of the model were confirmed recently by measurements for the first time of $\mathrm{Ca}^{2+}$ in the ER during cytosplasmic $\mathrm{Ca}^{2+}$ oscillations (Higgins et al. 2006).

In addition to the direct effect on $\mathrm{Ca}^{2+}$-activated $\mathrm{K}^{+}$channels, intracellular $\mathrm{Ca}^{2+}$ has two opposing effects on glucose metabolism in $\beta$-cells. Most of the $\mathrm{Ca}^{2+}$ that enters the cell is pumped out of the cell or into the ER by $\mathrm{Ca}^{2+}$ ATPases, which utilize ATP and thus decrease the intracellular ATP concentration (Detimary et al. 1998). $\mathrm{Ca}^{2+}$ that enters mitochondria through the $\mathrm{Ca}^{2+}$ uniporter depolarizes the mitochondrial inner membrane potential and thus reduces the driving force for mitochondrial ATP production (Magnus and Keizer 1997; Magnus and Keizer 1998; Krippeit-Drews et al. 2000; Kindmark et al. 2001). Once inside the mitochondria, free $\mathrm{Ca}^{2+}$ stimulates pyruvate dehydrogenase, isocitrate dehydrogenase, and $\alpha$-ketoglutarate dehydrogenase (Civelek et al. 1996; MacDonald et al. 2003), resulting in increased production of NADH, which can increase mitochondrial ATP production. Thus, $\mathrm{Ca}^{2+}$ has two opposing effects on the ATP/ADP ratio; one may dominate under some conditions, while the other action dominates in different conditions.

The ATP/ADP ratio is relevant for islet electrical activity due to the presence of ATP-sensitive $\mathrm{K}^{+}$ channels, which link the potential of the plasma membrane to the metabolic state of the $\beta$-cell (Ashcroft et al. 1984). Variations in the nucleotide ratio result in variation of the fraction of open K(ATP) channels. Thus, oscillations in the intracellular $\mathrm{Ca}^{2+}$ concentration can lead to oscillations in the ATP/ADP ratio, which can contribute to bursting through the action of hyperpolarizing K(ATP) current (Keizer and Magnus 1989; Henquin 1990; Smolen and Keizer 1992; Bertram and Sherman 2004). 

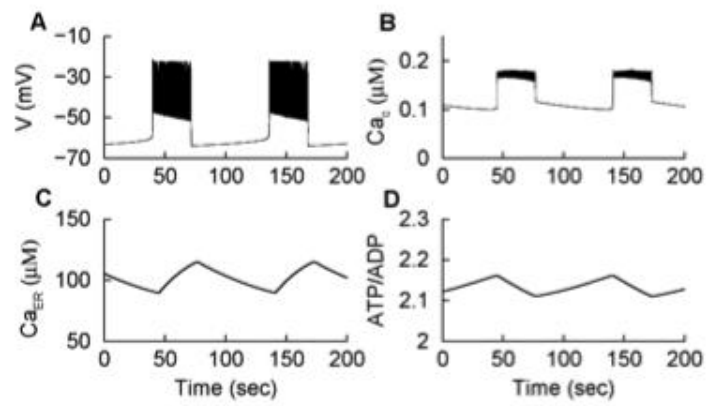

Figure 2: Model simulation of bursting illustrating the dynamics of membrane potential $(\mathrm{V})$, free cytosolic $\mathrm{Ca}^{2+}$ concentration (Cac), free $\mathrm{ER} \mathrm{Ca}^{2+}$ concentration (CaER), and the ATP/ADP concentration ratio. The model is described in Bertram and Sherman (2004) and the computer code can be downloaded from www.math.fsu.edu/ bertram/software/islet.

Figure 2 uses a mathematical model (Bertram and Sherman 2004) to demonstrate the dynamics of the variables described above. (Other models have been developed, postulating different burst mechanisms and highlighting other biochemical pathways (Fridlyand et al. 2003; Diederichs 2006; Cha et al. 2011).) Two bursts are shown in Fig. $2 \mathrm{~A}$ and the cytosolic free $\mathrm{Ca}^{2+}$ concentration (Cac) is shown in Fig. 2B. At the beginning of an active phase Cac quickly rises to a plateau that persists throughout the burst. Simultaneously, the ER free $\mathrm{Ca}^{2+}$ concentration (CaER) slowly increases as SERCA activity begins to fill the ER with $\mathrm{Ca}^{2+}$ (Fig. 2C). In contrast, the ATP/ADP ratio during a burst declines (Fig. 2D), since in this model the negative effect of $\mathrm{Ca}^{2+}$ on the ATP level dominates the positive effect. Both $\mathrm{K}(\mathrm{Ca})$ and $\mathrm{K}(\mathrm{ATP})$ currents, concomitantly activated by the increased $\mathrm{Ca}^{2+}$ and decreased ATP/ADP, respectively, combine to terminate the burst, after which $\mathrm{Cac}_{c}$ slowly declines. This slow decline reflects the passive release of $\mathrm{Ca}^{2+}$ from the ER during the silent phase of the burst, along with the removal of $\mathrm{Ca}^{2+}$ from the cell by $\mathrm{Ca}^{2+}$ pumps in the plasma membrane. Also, ATP/ADP increases during the silent phase, slowly turning off $\mathrm{K}(\mathrm{ATP})$ current. The combined effect of reducing $\mathrm{K}(\mathrm{Ca})$ and $\mathrm{K}(\mathrm{ATP})$ currents eventually leads to the initiation of a new active phase and the cycle restarts.

\section{METABOLIC OSCILLATIONS}

As described above and illustrated in Fig. 2, metabolic oscillations can arise from the effects of $\mathrm{Ca}^{2+}$ on the mitochondria and ATP utilization by pumps. In addition, there is considerable evidence for $\mathrm{Ca}^{2+}$-independent metabolic oscillations, reviewed in (Tornheim 1997; Bertram et al. 2007). The leading hypothesis is that glycolysis is oscillatory and is the primary mechanism underlying pulsatile insulin secretion from $\beta$-cells (Tornheim 1997). The M-type isoform of the glycolytic enzyme phosphofructokinase-1 (PFK1) is known to exhibit oscillatory activity in muscle extracts, as measured by oscillations in the levels of the PFK1 substrate fructose 6-phosphate (F6P) and the PFK1 product fructose 1,6-bisphosphate (F1,6BP) (Tornheim and Lowenstein 1974; Tornheim et al. 1991). The period of these oscillations, 5-10 min, is similar to the period of slow insulin oscillations (Tornheim 1997). The mechanism for the oscillatory activity of this isoform, which is the dominant PFK1 isoform in islets (Yaney et al. 1995), is the positive feedback of its product F1,6BP on phosphofructokinase activity (Fig. 3) and subsequent depletion of its substrate, F6P (Tornheim 1979; Smolen 1995; Westermark and Lansner 2003). While there is currently no direct evidence for glycolytic oscillations in $\beta$-cells, there is substantial evidence for metabolic oscillations. This come mainly from measurements of oscillations in several key metabolic variables, such as oxygen consumption (Longo et al. 1991; Ortsäter et al. 2000; Bergsten et al. 2002; Kennedy et al. 2002), ATP or the ATP/ADP ratio (Nilsson et al. 1996; Ainscow and Rutter 2002; JunttiBerggren et al. 2003), the mitochondrial inner membrane potential (Kindmark et al. 2001), lactate release (Chou et al. 1992), and NAD(P)H levels (Luciani et al. 2006). Additionally, it has been demonstrated that patients with homozygous PFK1-M deficiency are predisposed to type II diabetes (Ristow et al. 1997), and in a study on humans with an inherited deficiency of PFK1-M it was shown that oscillations in insulin secretion were impaired (Ristow et al. 1999). These data suggest that the origin of insulin secretion oscillations is glycolysis. In the second part of this chapter we discuss additional evidence for glycolytic oscillations, in the context of islet bursting. 


\section{Glucose}

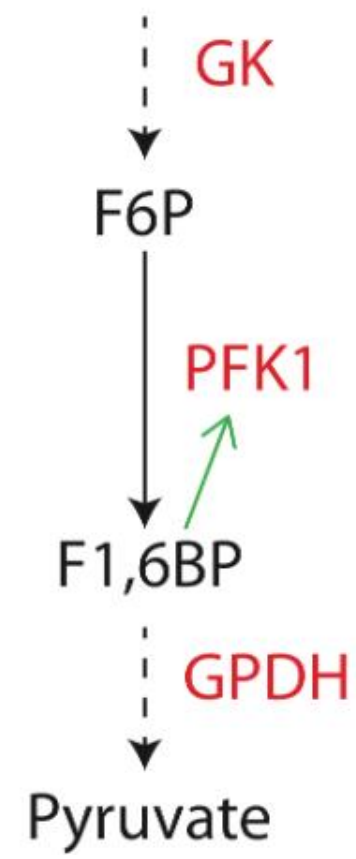

Figure 3: A few steps in glycolysis, focusing on the positive feedback of F1,6BP onto the allosteric enzyme PFK1 (green arrow). Dashed arrows indicate several steps in the glycolytic process, one of which is labeled. $\mathrm{GK}=$ glucokinase, $\mathrm{F} 6 \mathrm{P}=$ fructose 6 -phosphate, $\mathrm{F} 1,6 \mathrm{BP}=$ fructose

1,6-bisphosphate, GPDH=glyceraldehyde 3-phosphate dehydrogenase.

There is a long history of modeling of glycolytic oscillations, notably in yeast. Our model has a similar dynamical structure, based on fast positive feedback and slow negative feedback, to some of those models but differs in the identification of sources of feedback. In the models of Sel'kov (Sel'kov 1968) and Goldbeter and Lefever (Goldbeter and Lefever 1972) ATP was considered the substrate, whose depletion provided the negative feedback as F6P does in our model, and ADP was considered the product, which provided the positive feedback, as F1,6BP does in our model.

Such models can be combined with electrical activity to produce many of the patterns described here (Wierschem and Bertram 2004), but the biochemical interpretation is different. In our view, ATP acts rather as a negative modulator, which tends to shut down glycolysis when energy stores are replete, and ADP is a positive modulator, which activates glycolysis when ATP production falls behind metabolic demand. More fundamentally, we argue that $\beta$-cells, as metabolic sensors, differ from primary energyconsuming tissues such as muscle in that they need to activate metabolism whenever glucose is present even if the cell has all the ATP it needs. In this view, ATP and ADP are not suitable to serve as essential dynamic variables but do play significant roles as signaling molecules in regulating activity.

\section{THE DUAL OSCILLATOR MODEL FOR ISLET OSCILLATIONS}

Recent islet data provide the means to disentangle the influences of $\mathrm{Ca}^{2+}$ feedback and glycolysis on islet oscillations. Figure 4A shows compound $\mathrm{Ca}^{2+}$ oscillations, recorded from islets in $15 \mathrm{mM}$ glucose. There is a slow component (period $\sim 5 \mathrm{~min}$ ) with much faster oscillations superimposed on the slower plateaus. These compound oscillations have been frequently observed by a number of research groups (Valdeolmillos et al. 1989; Bergsten et al. 1994; Zhang et al. 2003; Beauvois et al. 2006), and reflect compound bursting oscillations, where fast bursts are clustered together into slower episodes (Henquin et al. 1982; Cook 1983). Figure 4B shows measurements of islet oxygen levels in $10 \mathrm{mM}$ glucose (Jung et al. 1999). Again there are large-amplitude slow oscillations (period of 3-4 min) with superimposed fast oscillations or "teeth". Similar compound oscillations have been observed in intra-islet glucose and in insulin secretion (Jung et al. 2000; Dahlgren et al. 2005), as assayed by $\mathrm{Zn}^{2+}$ efflux from $\beta$-cells. These data showing compound oscillations in a diversity of cellular variables suggest that compound oscillations are fundamental to islet function.

(1)

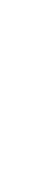


A
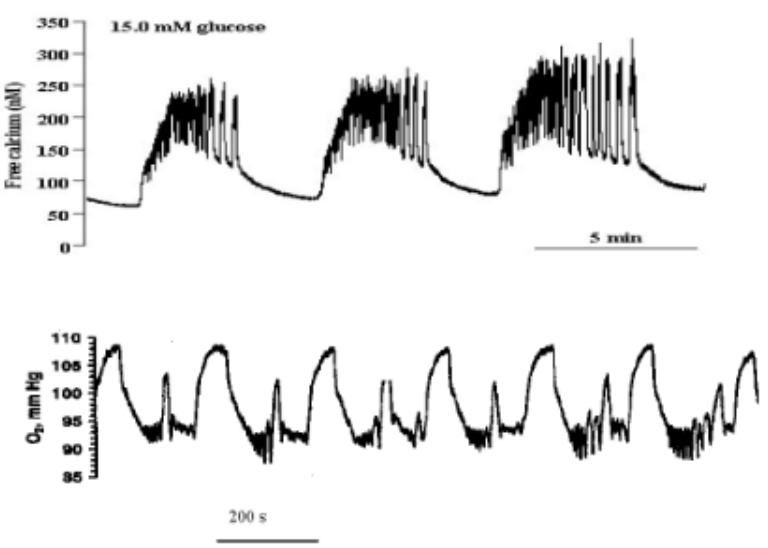

Figure 4: (A) Compound islet Ca2+ oscillations measured using fura-2/AM. The oscillations consist of slow episodes of fast oscillations. Reprinted from Bertram et al. (2004). (B) Slow oxygen oscillations with superimposed fast "teeth". Reprinted from Jung et al. (1999).

We have hypothesized that the slow component of the compound oscillations reflects oscillations in glycolysis, while the fast component is due to $\mathrm{Ca}^{2+}$ feedback onto ion channels and metabolism. This hypothesis has been implemented as a mathematical model, which we call the "Dual Oscillator Model" (Bertram et al. 2004; Bertram et al. 2007). The strongest evidence for this model is its ability to account for the wide range of time courses of $\mathrm{Ca}^{2+}$ and metabolic variables observed in glucose-stimulated islets both in vitro and in vivo. The fast oscillations introduced above do not have an underlying slow component. An example is shown in Fig. 5A. The Dual Oscillator Model reproduces this pattern (Fig. 5B) when glycolysis is non-oscillatory (Fig. 5C). The fast oscillations are mainly due to the effects of $\mathrm{Ca}^{2+}$ feedback onto $\mathrm{K}^{+}$channels as discussed earlier. Compound oscillations (Fig. 5D) are also produced by the model (Fig. 5E) and occur when both glycolysis and electrical activity are oscillatory (Fig. 5F) and

become phase-locked. The glycolytic oscillations provide the slow envelope and electrically-driven $\mathrm{Ca}^{2+}$ oscillations produce the fast pulses of $\mathrm{Ca}^{2+}$ that ride on the slow wave. A variant of compound bursting, not shown in Fig. 5, consists of fast bursting with a slowly-changing plateau fraction. This pattern, which we call "accordion bursting", has been observed in membrane potential, $\mathrm{Ca}^{2+}$, and oxygen (Henquin et al. 1982; Cook 1983; Bergsten et al. 1994; Kulkarni et al. 2004).
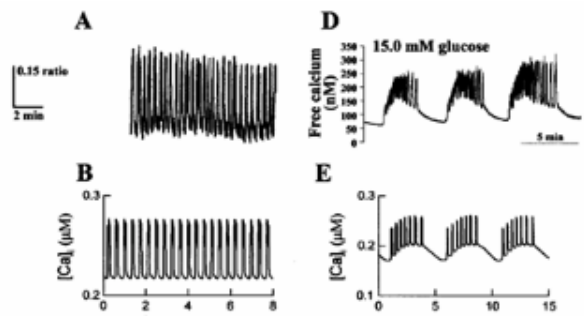

G

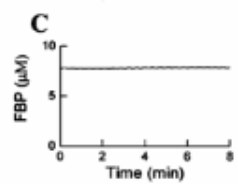

E

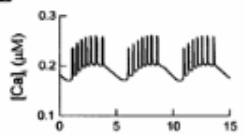

F

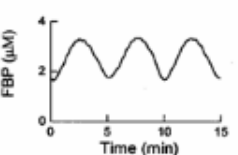

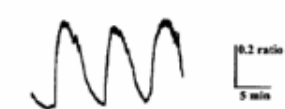

$\mathbf{H}$

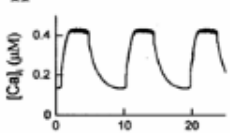

I

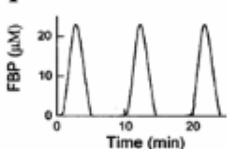

Figure 5: Three types of oscillations typically observed in islets. Top row of panels is from islet measurements of $\mathrm{Ca}^{2+}$ using fura-2/AM. Middle row shows simulations of $\mathrm{Ca}^{2+}$ oscillations using the Dual Oscillator Model. Bottom row shows simulations of the glycolytic intermediate fructose 1,6-bisphosphate (FBP), indicating that glycolysis is either stationary (C) or oscillatory $(F, I)$. Reprinted from Bertram et al. (2004), Nunemaker et al. (2005), and Bertram et al. (2007). $4 \mathrm{~B}$. The slow oscillations in the flux of metabolites from glycolysis to the mitochondria result in slow oscillations in $\mathrm{O} 2$ consumption by the mitochondrial electron transport chain. The $\mathrm{Ca}^{2+}$ feedback onto mitochondrial respiration also affects $\mathrm{O}_{2}$ consumption, resulting in the faster and smaller $\mathrm{O}_{2}$ oscillations. 
Pure slow oscillations (Fig. 5G) are also reproduced by the model (Fig. $5 \mathrm{H}$ ) when glycolysis is oscillatory (Fig. $5 \mathrm{l}$ ) and the cell is tonically active during the peak of glycolytic activity. Thus, a model that combines glycolytic oscillations with $\mathrm{Ca}^{2+}$-dependent oscillations can produce the three types of oscillatory patterns typically observed in islets, as well as faster oscillations in the $\mathrm{O}_{2}$ time course when in compound mode.

Accordion bursting, like compound bursting, is accompanied by $\mathrm{O}_{2}$ oscillations with fast teeth, but now present at all phases of the oscillation in both the model (Bertram et al. 2004), and in experiments (Kulkarni et al. 2004). The model thus suggests that the compound and accordion modes are just quantitative variants of the same underlying mechanisms. The former can be converted into the latter by reducing the conductance of the K(ATP) current, limiting its ability to repolarize the islets. It also supports the notion that $\beta$-cells have two oscillators that interact but can also occur independently of each other.

\section{GLUCOSE SENSING IN THE DUAL OSCILLATOR FRAMEWORK}

The concept of two semi-independent oscillators can be captured in a diagrammatic scheme (Fig 6) representing how the two sub-systems respond to changes in glucose. Depending on the glucose concentration, glycolysis can be low and steady, oscillatory, or high and steady. Similarly, the electrical activity can be off, oscillatory due to $\mathrm{Ca}^{2+}$ feedback, or in a continuous-spiking state. The two oscillators thus have glucose thresholds separating their different activity states. Increasing the glucose concentration can cause both the glycolytic and electrical subsystems to cross their thresholds, but not necessarily at the same glucose concentrations.

The canonical case is for the two oscillators to become activated in parallel. For example, in Case 1 of Fig. 6, when the islet is in $6 \mathrm{mM}$ glucose both the glycolytic oscillator (GO) and electrical oscillator (EO) are in their low activity states. When glucose is raised to $11 \mathrm{mM}$ both oscillators are activated, yielding slow $\mathrm{Ca}^{2+}$ oscillations. In this scenario, the electrical burst duty cycle or plateau fraction of the slow oscillation, a good indicator of the relative rate of insulin secretion, increases with glucose concentration, as seen in classical studies of fast bursting (Dean and Mathews 1970; Meissner and Schmelz 1974; Beigelman and Ribalet 1980). The increase in the glucose concentration in this regime has no effect on the amplitude of $\mathrm{Ca}^{2+}$ oscillations and little effect on the oscillation frequency (Nunemaker et al. 2006).

However, some islet responses have been observed to be transformed from fast to slow or compound oscillations when the glucose concentration was increased (Nunemaker et al. 2006). This dramatic increase in the oscillation period was accompanied by a large increase in the oscillation amplitude (Fig. 6, Case 2). We interpreted this as a switch from electrical to glycolytic oscillations, and termed this transformation "regime change". The diagrammatic representation in Fig. 6 indicates that this occurs when the threshold for the GO is shifted to the left of that for the EO. This may occur if glucokinase is relatively active or K(ATP) conductance is relatively low.

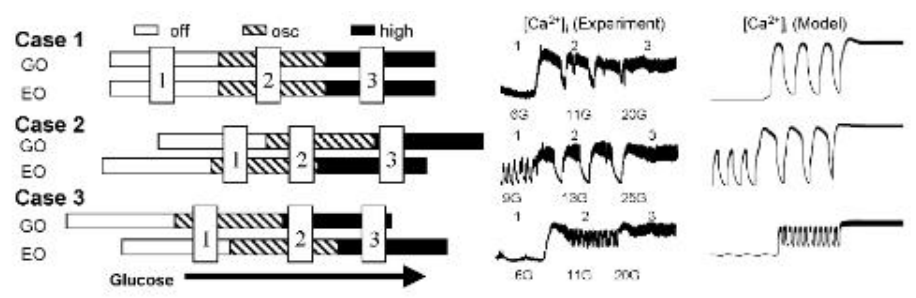

Figure 6: Schematic diagram illustrating the central hypothesis of the Dual Oscillator Model. In this hypothesis, there is an electrical subsystem that may be oscillatory (osc), or in a low (off) or high activity state. There is also a glycolytic subsystem that may be in a low or high stationary state or an oscillatory state. The glucose thresholds for the two subsystems need not be aligned, and different alignments can lead to different sequences of behaviors as the glucose concentration is increased. Reprinted from Nunemaker et al. (2006) and Bertram et al. (2007).

At $9 \mathrm{mM}$ glucose the $\mathrm{EO}$ is on, but the $\mathrm{GO}$ is off, so only fast $\mathrm{Ca}^{2+}$ oscillations result, driven by fast bursting electrical activity. When glucose is increased to $13 \mathrm{mM}$, the lower threshold for glycolytic oscillations is crossed and the fast $\mathrm{Ca}^{2+}$ oscillations combine with glycolytic oscillations to produce much slower and larger-amplitude slow or compound oscillations.

A final example is Case 3. In this islet, subthreshold $\mathrm{Ca}^{2+}$ oscillations are produced in $6 \mathrm{mM}$ glucose, which we believe are due to activation of the GO, while the EO is in a low activity (or silent) state. When glucose is increased to $11 \mathrm{mM}$ the lower threshold for electrical oscillations is crossed, initiating a fast oscillatory $\mathrm{Ca}^{2+}$ pattern. However, the upper threshold for glycolytic oscillations is also crossed, so the glycolytic oscillations stop. As a result, a fast oscillatory $\mathrm{Ca}^{2+}$ pattern is produced, with only a transient underlying slow component.

In all three cases, when glucose is raised to $20 \mathrm{mM}$ or higher the system moves past the upper thresholds for both the GO and the EO, so there are neither electrical bursting oscillations nor glycolytic oscillations, and the islet generates a continuous spiking pattern. The Dual Oscillator Model accounts for each of these regime-change behaviors, as shown in the right column of Fig. 6.

\section{METABOLIC OSCILLATIONS CAN BE RESCUED BY CALCIUM}

Given that metabolic oscillations can be driven by either $\mathrm{Ca}^{2+}$ feedback onto ATP production/utilization or by an independent mechanism such as glycolytic oscillations, experimental tests have been developed to determine which of these occurs in islets. One such test takes the strategy of 
manipulating the islet so that $\mathrm{Ca}^{2+}$ oscillations do not occur. Figure 7 shows that when the islet is hyperpolarized with the K(ATP) channel agonist diazoxide $(250 \mu \mathrm{M})$ the oscillations in $\mathrm{Ca}^{2+}$ concentration, as measured by Fura-2 fluorescence, and metabolism, as measured by $\mathrm{NAD}(\mathrm{P}) \mathrm{H}$ autofluorescence, are both terminated (Luciani et al. 2006; Bertram et al. 2007). A similar test was performed by Kennedy and colleagues, except that they used an oxygen-sensing electrode to monitor metabolism (Kennedy et al. 2002). They also found that membrane hyperpolarization terminated metabolic oscillations.
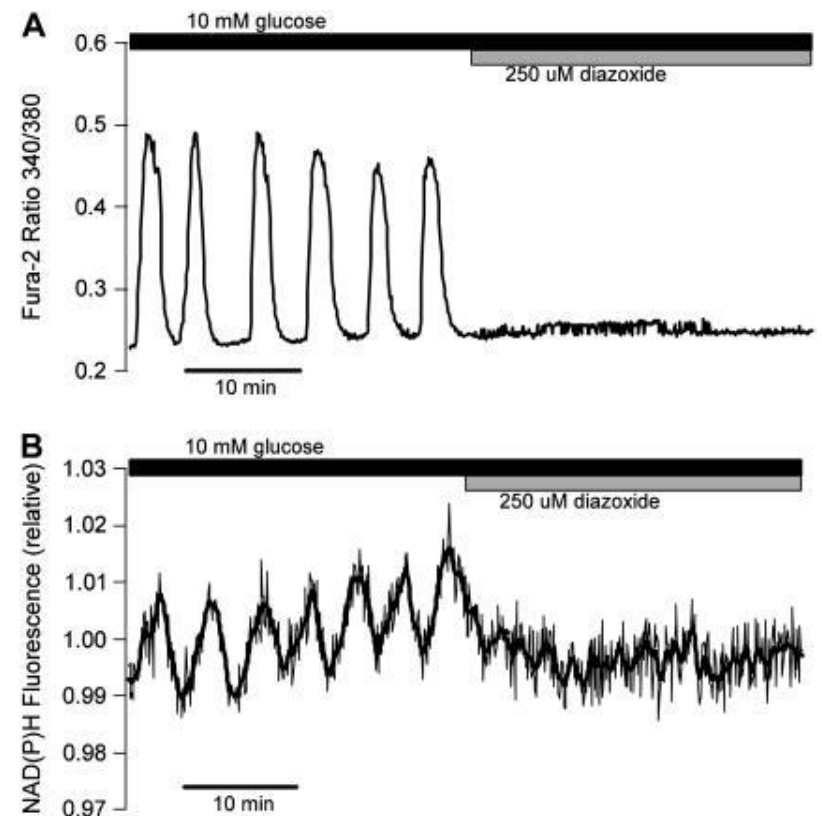

Figure 7: Measurements of (A) fura-2 fluorescence and (B) $N A D(P) H$ autofluorescence demonstrate that islet hyperpolarization with diazoxide can terminate metabolic oscillations. Reprinted from Bertram et al. (2007).

It is tempting to conclude from these data that metabolic oscillations must be driven by $\mathrm{Ca}^{2+}$ oscillations, and in the absence of a mathematical model this seems like a logical conclusion. Surprisingly, though, model simulations we carried out using the Dual Oscillator Model showed that under some conditions islet hyperpolarization, as was done in Fig. 7, would in fact terminate metabolic oscillations even if they were driven by glycolytic oscillations (Bertram et al. 2007). This is because the decline in $\mathrm{Ca}^{2+}$ influx that accompanies hyperpolarization reduces ATP utilization by $\mathrm{Ca}^{2+}$ pumps. This results in an increase in the cytosolic ATP concentration, and ATP inhibits the enzyme, PFK1, responsible for glycolytic oscillations.

Thus, cessation of metabolic oscillations by blocking $\mathrm{Ca}^{2+}$ oscillations does not imply that $\mathrm{Ca}^{2+}$ oscillations are necessary for metabolic oscillations, but the converse is valid. If metabolic oscillations are observed when $\mathrm{Ca}^{2+}$ is clamped, it must mean that the metabolic oscillations are not merely a reflection of $\mathrm{Ca}^{2+}$ oscillations. Indeed, the Dual Oscillator Model predicts that, in many cases, it should be possible to have metabolic oscillations driven by glycolysis even though the $\mathrm{Ca}^{2+}$ concentration is clamped. This requires, however, that the level at which $\mathrm{Ca}^{2+}$ is clamped be sufficiently high so that the PFK1 enzyme is not inhibited by the elevated ATP that accompanies cessation of $\mathrm{Ca}^{2+}$ pumping. With this in mind, the model was used to design an experiment to truly test whether metabolic oscillations can exist in the absence of $\mathrm{Ca}^{2+}$ oscillations (Merrins et al. 2010). In the simulation shown in Fig. 8, a model islet exhibiting compound oscillations in stimulatory glucose was hyperpolarized by increasing the fraction of activated K(ATP) channels (simulating the application of diazoxide). This reduced the cytosolic $\mathrm{Ca}^{2+}$ concentration, which in turn increased cytosolic ATP concentration through the reduced activity of $\mathrm{Ca}^{2+}$ pumps. Metabolic oscillations, as reflected in the mitochondrial NADH concentration, were thus terminated. The model islet was subsequently depolarized by increasing the Nernst potential for $\mathrm{K}^{+}$ (simulating the application of $\mathrm{KCl}$ ). The depolarization activates $\mathrm{L}$-type $\mathrm{Ca}^{2+}$ channels in the plasma membrane, raising the level of $\mathrm{Ca}^{2+}$ in the cytosol (Fig. 8A). This induced increased activity of the $\mathrm{Ca}^{2+}$ pumps, increasing ATP hydrolysis and lowering the ATP level (Fig. 8B). The resultant disinhibition of PFK1 allowed glycolytic oscillations to re-emerge (Fig. 8C). Importantly, these oscillations persisted in the absence of $\mathrm{Ca}^{2+}$ oscillations. The combination of diazoxide and $\mathrm{KCl}$ effectively clamps the $\mathrm{Ca}^{2+}:$ the diazoxide cuts the link between metabolism (i.e., ATP) and the membrane potential by opening the $\mathrm{K}(\mathrm{ATP})$ channels, and the $\mathrm{KCl}$ inhibits action potential production and the accompanying $\mathrm{Ca}^{2+}$ oscillations that would result from spiking-induced $\mathrm{Ca}^{2+}$ influx. 
A

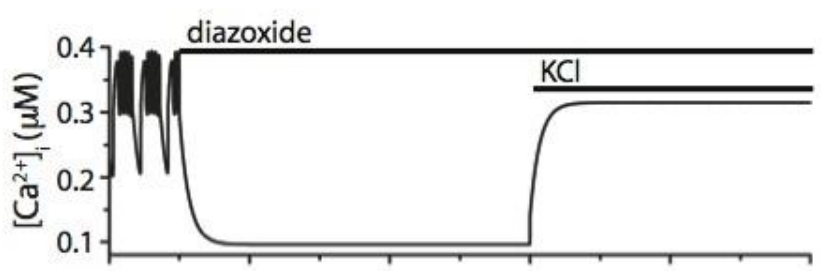

B

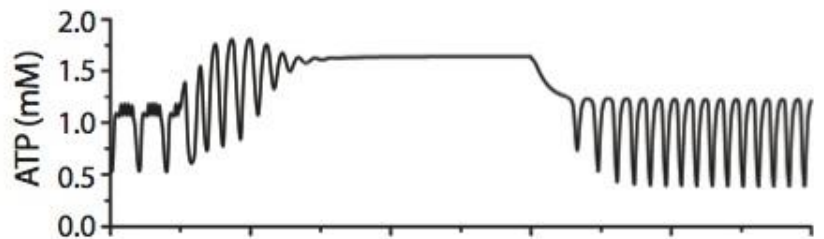

C

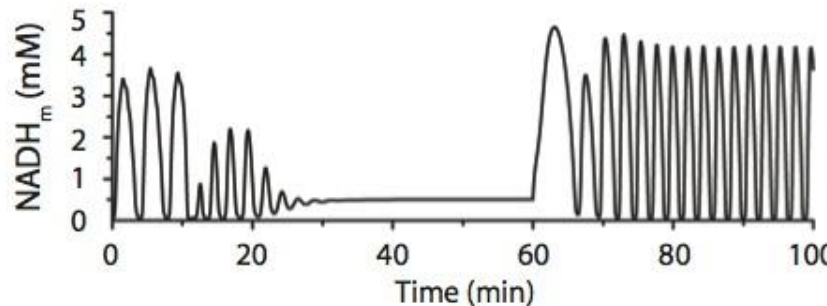

Figure 8: Mathematical simulations demonstrating how increasing the level of intracellular free $\mathrm{Ca}^{2+}$ can rescue metabolic oscillations. Simulated application of diazoxide hyperpolarizes the islet, lowering the intracellular $\mathrm{Ca}^{2+}$ concentration $(\mathrm{A})$. This greatly reduces the pumping needed to remove $\mathrm{Ca}^{2+}$ from the $\beta$-cell, thereby decreasing ATP utilization and increasing the ATP concentration in the cytosol (B). The result of this is disinhibition of PFK1, which allows glycolytic oscillations to emerge (C). Reprinted from Merrins et al. (2010).

The prediction that glycolytic oscillations can be rescued by elevating the intracellular $\mathrm{Ca}^{2+}$ level was tested experimentally (Merrins et al. 2010). Metabolic oscillations as measured through NAD(P)H autofluorescence were terminated by hyperpolarization (application of $200 \mu \mathrm{M}$ diazoxide) in about two-thirds of the islets but persisted in the remainder. Subsequent application of $\mathrm{KCl}$ increased the level of intracellular $\mathrm{Ca}^{2+}$ while prohibiting $\mathrm{Ca}^{2+}$ oscillations (Fig. 9A, with different concentrations of $\mathrm{KCl}$ ). In about one-half of the islets in which $\mathrm{Ca}^{2+}$ oscillations had been terminated, metabolic oscillations were restored when the intracellular $\mathrm{Ca}^{2+}$ concentration was raised (Fig. 9B). Thus, it was demonstrated that metabolic oscillations can occur in islets in the absence of $\mathrm{Ca}^{2+}$ oscillations.

The experiments, however, raised two new questions: Why did slow metabolic oscillations persist in some islets but not in others, and why did raising $\mathrm{Ca}^{2+}$ restore oscillations in some islets but not in others? In the latter case, it is possible that oscillations would have been restored if a different $\mathrm{KCl}$ concentration had been used, but further mathematical analysis suggests another possibility. The model was found to support yet another type of slow metabolic oscillation that is neither secondary to $\mathrm{Ca}^{2+}$ oscillations nor fully independent of $\mathrm{Ca}^{2+}$ oscillations. In this regime, neither of the electrical and metabolic oscillators is able to oscillate on its own, but only a reciprocal interaction between the two can result in oscillations (M. Watts, B. Fendler, R. Bertram, and A. Sherman, submitted for publication). It remains to be tested experimentally whether such a regime exists in real islets.
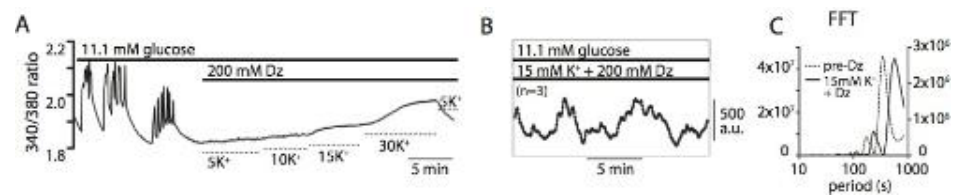

Figure 9: Experimental test of the model prediction made in Fig. 8. (A) Compound $\mathrm{Ca}^{2+}$ oscillations are terminated by diazoxide $(200 \mu \mathrm{M})$. The $\mathrm{Ca}^{2+}$ concentration is elevated when $\mathrm{KCl}$ is added to the bath, but $\mathrm{Ca}^{2+}$ oscillations are not initiated. (B) Oscillations in NAD(P)H autofluorescence can be initiated in the presence of diazoxide when $\mathrm{KCl}$ has been added to depolarize the cell and increase the level of $\mathrm{Ca}^{2+}$. (C) Fourier power spectrum of the NAD(P)H fluorescence prior to the addition of diazoxide (dotted) and after diazoxide plus $\mathrm{KCl}$. Large peaks occur at the period of slow metabolic oscillations. Reprinted from Merrins et al. (2010). 
One way to determine if glycolysis is the source of metabolic oscillations is to manipulate it in such a way that glycolytic oscillations, if they exist, are altered in a predictable way. This was done in an indirect way in the experiments described above, through changes in the intracellular $\mathrm{Ca}^{2+}$ level, which acts on an inhibitor (ATP) of the key rhythmogenic enzyme PFK1. A second approach is to interfere with the feedback loop that is responsible for the production of putative glycolytic oscillations. This feedback comes from F1,6BP allosterically activating the enzyme that produced it, PFK1. The loop would be broken and the oscillation eliminated if this feedback were removed. In a similar vein, if the feedback were weakened through the actions of another molecule that competes with F1,6BP for the same binding site on PFK1, then the properties of the oscillation (e.g., oscillation frequency and amplitude) would change. A mathematical model of the reaction would allow one to predict the effect of the competitive activator, and if islet $\mathrm{Ca}^{2+}$ oscillations were effected in the same way, then this would provide evidence that the $\mathrm{Ca}^{2+}$ oscillations are driven by glycolytic oscillations.

This approach was taken in a recent study, which made use of the bifunctional enzyme phosphofructokinase-2/fructobisphosphatase-2, which we call PFK2/FBPase2 or BIF2 (Fig. 10). This enzyme has a kinase on the N-terminal (PFK2) and a phosphatase on the C-terminal (FBPase2). The kinase converts F6P to fructose 2,6-bisphosphate (F2,6BP) and is the sole source of F2,6BP in the cell. The phosphatase end of the enzyme does the opposite. Importantly, F2,6BP is an allosteric activator of PFK1, and is a more potent activator of PFK1 than is F1,6BP (Malisse et al. 1982; Foe et al. 1983; Sener et al. 1984). It is therefore an ideal molecule for weakening the positive feedback of F1,6,BP onto PFK1 and thus changing the properties of putative glycolytic oscillations.

\section{Glucose}

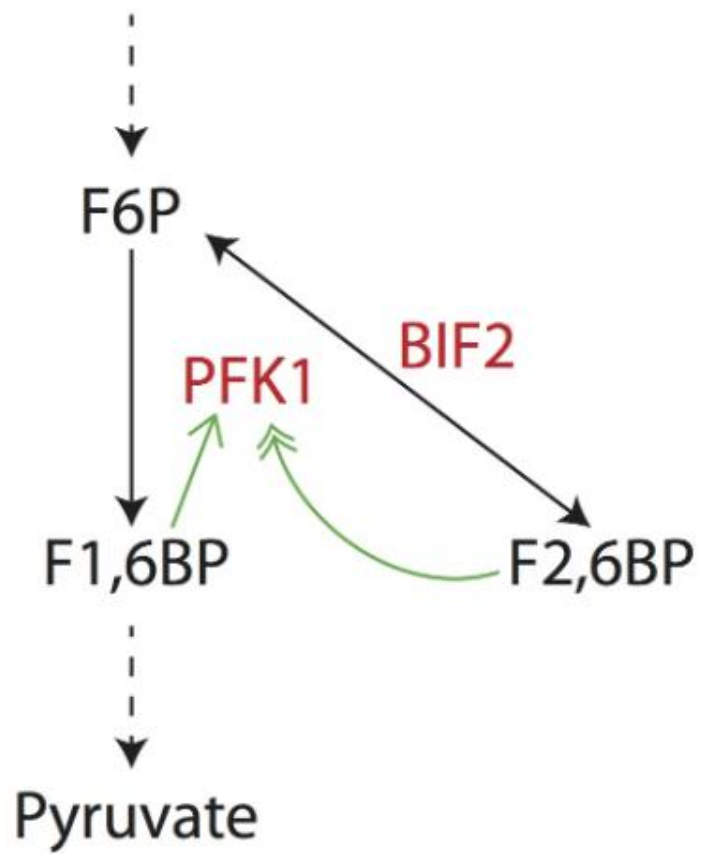

Figure 10: Illustration showing that fructose 2,6-bisphosphate (F2,6BP) activates PFK1 (double green arrow) more strongly than does F1,6BP. The F2,6BP is generated by the enzyme PFK2/FBPase2 (BIF2)

In (Merrins et al. 2012), mutants of the islet isoform of PFK2/FBPase2 (Sakurai et al. 1996; Arden et al. 2008) were expressed in mouse islets using an adenoviral delivery system. Four mutants were examined, but we focus here on only two. One mutant (DD-PFK2) contained only the PFK2 domain, tagged at the N-terminal with a Degradation Domain (DD), which permits transcription and translation, but prevents accumulation of functional protein in the cytosol due to rapid proteasomal degradation. This degradation can be inhibited by a small cell-permeant molecule called Shield1 (Banaszynski et al. 2006). The other mutant (DD-FBPase2) contained only the FBPase2 domain, also tagged at the N-terminal with DD. Adenoviral delivery of the DD-PFK2 mutant in the presence of Shield1 would then result in overproduction of PFK2, and an increase in the concentration of F2,6BP. In the absence of Shield1, functional PFK2 protein would not accumulate, so delivery of DD-PFK2 without Shield1 serves as a control. A similar strategy was used for DD-FBPase2, which when delivered in the presence of Shield1 increases FBPase 2 concentration in the cell, resulting in a reduction in the F2,6BP concentration. One advantage of these truncation mutants is that neither activates glucokinase (Merrins et al. 2012), as the full BIF2 molecule is known to do (Langer et al. 2010).

A mathematical model of the allosteric PFK1 reaction was used to predict the effects on glycolytic oscillations of increasing or decreasing the concentration of the competitive allosteric activator F2,6BP. The model predicted that increasing F2,6BP should make oscillations faster and smaller in amplitude, and if F2,6BP was increased too much the oscillations would be terminated. Decreasing the F2,6BP concentration should have the opposite effect, making glycolytic oscillations slower and larger in amplitude. A similar prediction was made using the full Dual Oscillator Model, where now the final readout was the cytosolic $\mathrm{Ca}^{2+}$ concentration.

Model predictions were tested using the DD-PFK2 and DD-FBPase2 mutants. When DD-PFK2 was 
expressed in mouse islets, the period of the $\mathrm{Ca}^{2+}$ oscillations we observed was significantly smaller in the presence of Shield1 than in its absence, and the amplitude of the oscillations was significantly reduced (Fig. 11). That is, when functional PFK2 protein was produced (Shield1 present), which should increase the production of $\mathrm{F} 2,6 \mathrm{BP}, \mathrm{Ca}^{2+}$ oscillations were faster and smaller compared with islets in which Shield1 was absent. When DD-FBPase 2 was expressed, the period of $\mathrm{Ca}^{2+}$ oscillations was significantly larger in the presence of Shield1 than in its absence, and the amplitude of the oscillations was significantly increased (Fig. 11). These results match the predictions of the Dual Oscillator Model. Thus, for the first time, it was shown that manipulations that should make $\mathrm{Ca}^{2+}$ oscillations faster/slower if the oscillations are the result of glycolytic oscillations did indeed make the oscillations faster/slower.
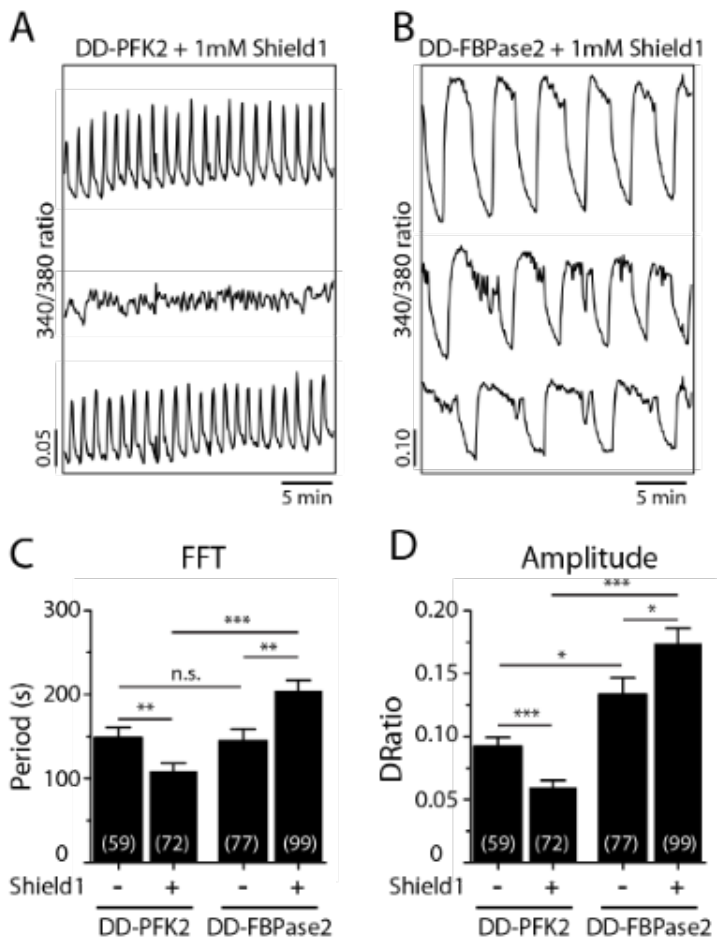

Figure 11: (A) Expression of DD-PFK2 with Shield1 results in the production of F2,6BP which makes $\mathrm{Ca}^{2+}$ oscillations smaller and faster (left) compared with islets expressing DD-FBPase2 with Shield1 (right). (B) Fast fourier transform of $\mathrm{Ca}^{2+}$ oscillation periods in islets expressing DD-PFK2 or DD-FBPase2 (with or without Shield1). (C) Amplitude of $\mathrm{Ca}^{2+}$ oscillations. Reprinted from Merrins et al. (2012).

\section{SUMMARY}

The Dual Oscillator Model, developed over a period of time from simpler $\mathrm{Ca}^{2+}$-dependent models of fast bursting to account for slower and more complex patterns of islet oscillatory behavior, has done so successfully, while also clarifying the complex relationship between intracellular $\mathrm{Ca}^{2+}, \beta$-cell ion channels, and intrinsic oscillations in islet glucose metabolism. The model also clarifies the results of experiments that would be hard to interpret or open to misinterpretation in the absence of a model. In addition to the studies described above, recent work used the DOM to interpret islet electrophysiology experiments, and to understand the role played by gap-junctional coupling between $\beta$-cells (Ren et al., American Journal of Physiology, in press). It remains to be determined how functional properties of human islets differ from mouse islets, and whether there are similar mechanisms driving oscillations in islets from the two species. It is also yet to be seen what role the model will have in understanding islet dysfunction in models of diabetes.

\section{Acknowledgments}

The authors thank Bernard Fendler, Pranay Goel, Matthew Merrins, Craig Nunemaker, Morten Gram Pedersen, Brad Peercy, and Min Zhang, who each collaborated on some of the work described herein RB is supported by NIH grant DK80714. AS is supported by the Intramural Research Program of the NIH (NIDDK). LS is supported by NIH grant RO1 DK 46409.

\section{References}

Ainscow, E. K. and G. A. Rutter (2002). "Glucose-stimulated oscillations in free cytosolic ATP concentration imaged in single islet $\beta$-cells." Diabetes 51: S162-S170.

Ämmälä, C., F. M. Ashcroft and P. Rorsman (1993). "Calcium-independent potentiation of insulin release by cyclic AMP in single $\beta$-cells." Nature 363: 356-358. 
Arden, C., L. J. Hampson, G. C. Huang, J. A. M. Shaw, A. Aldibbiat, G. Holliman, D. Manas, S. Khan, A. J. Lange and L. Agius (2008). "A role for PFK-2/FBPase-2, as distinct from fructose 2,6-bisphosphate, in regulation of insulin secretion in pancreatic beta-cells." Biochem. J. 411: 41-51.

Arredouani, A., J.-C. Henquin and P. Gilon (2002). "Contribution of the endoplasmic reticulum to the glucose-induced $\left[\mathrm{Ca}^{2+}\right] \mathrm{c}$ response in mouse pancreatic islets." Am. J. Physiol. 282: E982-E991.

Ashcroft, F. M., D. E. Harrison and S. J. H. Ashcroft (1984). "Glucose induces closure of single potassium channels in isolated rat pancreatic $\beta$-cells." Nature 312: 446-448.

Banaszynski, L. A., L.-C. Chen, L. A. Maynard-Smith, A. G. L. Ooi and T. J. Wandless (2006). "A rapid, reversible, and tunable method to regulate protein function in living cells using synthetic small molecules." Cell 126: 995-1004.

Beauvois, M. C., C. Merezak, J.-C. Jonas, M. A. Ravier and J.-C. Henquin (2006). "Glucose-induced mixed $\left[\mathrm{Ca}^{2+}\right]_{c}$ oscillations in mouse b-cells are controlled by the membrane potential and the SERCA3 $\mathrm{Ca}^{2+}$-ATPase of the endoplasmic reticulum." Am. J. Physiol. 290: C1503-C1511.

Beigelman, P. M. and B. Ribalet (1980). "Beta-cell electrical activity in response to high glucose concentration." Diabetes 29: 263-265.

Bergsten, P. (1995). "Slow and fast oscillations of cytoplasmic $\mathrm{Ca}^{2+}$ in pancreatic islets correspond to pulsatile insulin release." Am. J. Physiol. 268: E282-E287.

Bergsten, P. (1998). "Glucose-induced pulsatile insulin release from single islets at stable and oscillatory cytoplasmic $\mathrm{Ca}^{2+}$." Am. J. Physiol. 274: E796-E800.

Bergsten, P., E. Grapengiesser, E. Gylfe, A. Tengholm and B. Hellman (1994). "Synchronous oscillations of cytoplasmic $\mathrm{Ca}^{2+}$ and insulin release in glucose-stimulated pancreatic islets." J. Biol. Chem. 269: 8749-8753.

Bergsten, P. and B. Hellman (1993). "Glucose-induced amplitude regulation of pulsatile insulin secretion from individual pancreatic islets." Diabetes 42: 670-674.

Bergsten, P., J. Westerlund, P. Liss and P.-O. Carlsson (2002). "Primary in vivo oscillations of metabolism in the pancreas." Diabetes 51: 699-703.

Bertram, R. and R. C. Arceo II (2008). "A mathematical study of the differential effects of two SERCA isoforms on $\mathrm{Ca}^{2+}$ oscillations in pancreatic islets." Bull. Math. Biol. 70: 1251-1271.

Bertram, R., L. Satin, M. Zhang, P. Smolen and A. Sherman (2004). "Calcium and glycolysis mediate multiple bursting modes in pancreatic islets." Biophys. J. 87: 3074-3087.

Bertram, R., L. S. Satin, M. G. Pedersen, D. S. Luciani and A. Sherman (2007). "Interaction of glycolysis and mitochondrial respiration in metabolic oscillations of pancreatic islets." Biophys. J. 92: 1544-1555.

Bertram, R. and A. Sherman (2004). "A calcium-based phantom bursting model for pancreatic islets." Bull. Math. Biol. 66: 1313-1344.

Bertram, R. and A. Sherman (2004). "Filtering of calcium transients by the endoplasmic reticulum in pancreatic $\beta$-cells." Biophys. J. 87: 3775-3785.

Bertram, R., A. Sherman and L. S. Satin (2007). "Metabolic and electrical oscillations: partners in controlling pulsatile insulin secretion." Am. J. Physiol. 293: E890-E900.

Cha, C. Y., Y. Nakamura, Y. Himeno, J. Wang, S. Fujimoto, N. Inagaki, Y. E. Earm and A. Noma (2011).

"Ionic mechanisms and $\mathrm{Ca}^{2+}$ dynamics underlying the glucose response of pancreatic $\beta$ cells: a simulation study." J. Gen. Physiol. 138: 21-37.

Chay, T. R. and J. Keizer (1983). "Minimal model for membrane oscillations in the pancreatic $\beta$-cell." Biophys. J. 42: 181-190.

Chay, T. R. and J. Keizer (1983). "Minimal model for membrane oscillations in the pancreatic $\beta$-cell." Biophys. J. 42: 181-190.

Chou, H.-F., N. Berman and E. Ipp (1992). "Oscillations of lactate released from islets of Langerhans: evidence for oscillatory glycolysis in $\beta$-cells." Am. J. Physiol. 262: E800-E805.

Civelek, V. N., J. T. Deeney, N. J. Shalosky, K. Tornheim, R. G. Hansford, M. Prentki and B. E. Corkey

(1996). "Regulation of pancreatic beta-cell mitochondrial metabolism: influence of $\mathrm{Ca}^{2+}$, substrate and ADP." Biochem. J. 318: 615-621.

Cook, D. L. (1983). "Isolated islets of Langerhans have slow oscillations of electrical activity." Metabolism 32: 681-685.

Dahlgren, G. M., L. M. Kauri and R. T. Kennedy (2005). "Substrate effects on oscillations in metabolism, calcium and secretion in single mouse islets of Langerhans." Biochim. Biophys. Acta 1724: 23-36.

Dean, P. M. and E. K. Mathews (1970). "Glucose-induced electrical activity in pancreatic islet cells." $\underline{\text { J. }}$ Physiol. 210: 255-264.

Detimary, P., P. Gilon and J. C. Henquin (1998). "Interplay between cytoplasmic $\mathrm{Ca}^{2+}$ and the ATP/ADP ratio: a feedback control mechanism in mouse pancreatic islets." Biochem. J. 333: 269-274.

Diederichs, F. (2006). "Mathematical simulation of membrane processes and metabolic fluxes of the pancreatic $\beta$-cell." Bull. Math. Biol. 68: 1779-1818.

Eaton, R. P., R. C. Allen and D. S. Schade (1983). "Hepatic removal of insulin in normal man: dose response to endogenous insulin secretion." J. Clin. Endocrinol. Metab. 56: 1294-1300.

Foe, L. G., S. P. Latshaw and R. G. Kemp (1983). "Binding of hexose bisphosphates to muscle phosphofructokinase." Biochemistry 22: 4601-4606.

Fridlyand, L. E., N. Tamarina and L. H. Phillipson (2003). "Modeling the $\mathrm{Ca}^{2+}$ flux in pancreatic $\beta$-cells: role of the plasma membrane and intracellular stores." Am. J. Physiol. 285: E138-E154.

Gilon, P., A. Arredouani, P. Gailly, J. Gromada and J.-C. Henquin (1999). "Uptake and release of $\mathrm{Ca}^{2+}$ by the endoplasmic reticulum contribute to the oscillations of the cytosolic $\mathrm{Ca}^{2+}$ concentration triggered by 
$\mathrm{Ca}^{2+}$ influx in the electrically excitable pancreatic $\beta$-cell." J. Biol. Chem. 274: 20197-20205. Gilon, P., R. M. Shepherd and J. C. Henquin (1993). "Oscillations of secretion driven by oscillations of cytoplasmic $\mathrm{Ca}^{2+}$ as evidenced in single pancreatic islets." J. Biol. Chem. 268: 22265-22268. Goforth, P. B., R. Bertram, F. A. Khan, M. Zhang, A. Sherman and L. S. Satin (2002). "Calcium-activated $\mathrm{K}^{+}$channels of mouse $\beta$-cells are controlled by both store and cytoplasmic $\mathrm{Ca}^{2+}$ : experimental and theoretical studies." J. Gen. Physiol. 114: 759-769.

Goldbeter, A. and R. Lefever (1972). "Dissipative structures for an allosteric model; application to glycolytic oscillations." Biophys. J. 12: 1302-1315.

Göpel, S. O., T. Kanno, S. Barg, L. Eliasson, J. Galvanovskis, E. Renström and P. Rorsman (1999).

"Activation of $\mathrm{Ca}^{2+}$-dependent $\mathrm{K}^{+}$channels contributes to rhythmic firing of action potentials in mouse pancreatic $\beta$-cells." J. Gen. Physiol. 114: 759-769.

Henquin, J. C. (1990). "Glucose-induced electrical activity in beta-cells: feedback control of ATP-sensitive $\mathrm{K}^{+}$channels by $\mathrm{Ca}^{2+}$ ?" Diabetes 39: 1457-1460.

Henquin, J. C., H. P. Meissner and W. Schmeer (1982). "Cyclic variations of glucose-induced electrical activity in pancreatic $\beta$ cells." Pflügers Archiv. 393: 322-327.

Higgins, E. R., M. B. Cannell and J. Sneyd (2006). "A buffering SERCA pump in models of calcium dynamics." Biophys. J. 91: 151-163.

Jung, S.-K., C. A. Aspinwall and R. T. Kennedy (1999). "Detection of multiple patterns of oscillatory oxygen consumption in single mouse islets of Langerhans." Biochem. Biophys. Res. Commun. 259 331-335.

Jung, S.-K., L. M. Kauri, W.-J. Qian and R. T. Kennedy (2000). "Correlated oscillations in glucose consumption, oxygen consumption, and intracellular free $\mathrm{Ca}^{2+}$ in single islets of Langerhans." J. Biol. Chem. 275: 6642-6650.

Juntti-Berggren, L., D.-L. Webb, P. O. G. Arkhammar, V. Schultz, E. K. H. Schweda, K. Tornheim and P.-O. Berggren (2003). "Dihydroxyacetone-induced oscillations in cytoplasmic free $\mathrm{Ca}^{2+}$ and the ATP/ADP ratio in pancreatic $\beta$-cells at substimulatory glucose." J. Biol. Chem. 278: 40710-40716.

Keizer, J. and G. De Young (1993). "Effect of voltage-gated plasma membrane $\mathrm{Ca}^{2+}$ fluxes on IP3-linked $\mathrm{Ca}^{2+}$ oscillations." Cell Calcium 14: 397-410.

Keizer, J. and G. Magnus (1989). "The ATP-sensitive potassium channel and bursting in the pancreatic beta cell." Biophys. J. 56: 229-242.

Kennedy, R. T., L. M. Kauri, G. M. Dahlgren and S.-K. Jung (2002). "Metabolic oscillations in $\beta$-cells." Diabetes 51: S152-S161.

Kindmark, H., M. Köhler, G. Brown, R. Bränström, O. Larsson and P.-O. Berggren (2001). "Glucose-

induced oscillations in cytoplasmic free $\mathrm{Ca}^{2+}$ concentration precede oscillations in mitochondrial membrane potential in the pancreatic $\beta$-cell." J. Biol. Chem. 276: 34530-34536.

Krippeit-Drews, P., M. Dufer and G. Drews (2000). "Parallel oscillations of intracellular calcium activity and mitochondrial membrane potential in mouse pancreatic $\beta$-cells." Biochem. Biophys. Res. Commun. 267: 179-183.

Kulkarni, R. N., M. G. Roper, G. M. Dahlgren, D. Q. Shih, L. M. Kauri, J. L. Peters, M. Stoffel and R. T. Kennedy (2004). "Islet secretory defect in insulin receptor substrate 1 null mice is linked with reduced calcium signaling and expression of sarco(endo)plasmic reticulum $\mathrm{Ca}^{2+}$-ATPase (SERCA)-2b and $-3 . "$ Diabetes 53: 1517-1525.

Lang, D. A., D. R. Matthews, M. Burnett and R. C. Turner (1981). "Brief, irregular oscillations of basal plasma insulin and glucose concentrations in diabetic man." Diabetes 30: 435-439.

Langer, S., M. T. Kaminski, S. Lenzen and S. Baltrusch (2010). "Endogenous activation of glucokinase by 6-phosphofructo-2-kinase/fructose-2,6-bisphosphatase is glucose dependent." Mol. Endocrinol. 24: 1988-1997.

Longo, E. A., K. Tornheim, J. T. Deeney, B. A. Varnum, D. Tillotson, M. Prentki and B. E. Corkey (1991). "Oscillations in cytosolic free $\mathrm{Ca}^{2+}$, oxygen consumption, and insulin secretion in glucose-stimulated rat pancreatic islets." J. Biol. Chem. 266: 9314-9319.

Luciani, D. S., S. Misler and K. S. Polonsky (2006). "Ca ${ }^{2+}$ controls slow NAD(P)H oscillations in glucosestimulated mouse pancreatic islets." J. Physiol. 572: 379-392.

MacDonald, M. J., L. A. Fahien, J. D. Buss, N. M. Hasan, M. J. Fallon and M. A. Kendrick (2003). "Citrate oscillates in liver and pancreatic beta cell mitochondria and in INS-1 insulinoma cells." J. Biol. Chem. 278 : $51894-51900$

Magnus, G. and J. Keizer (1997). "Minimal model of $\beta$-cell mitochondrial $\mathrm{Ca}^{2+}$ handling." Am. J. Physiol. 273: C717-C733.

Magnus, G. and J. Keizer (1998). "Model of $\beta$-cell mitochondrial calcium handling and electrical activity. I. Cytoplasmic variables." Am. J. Physiol. 274: C1158-C1173.

Malisse, W. J., F. Malaisse-Lagae and A. Sener (1982). "Glucose-induced accumulation of fructose2,6-bisphosphate in pancreatic islets." Diabetes 31: 90-93.

Matthews, D. R., D. A. Lang, M. Burnett and R. C. Turner (1983). "Control of pulsatile insulin secretion in man." Diabetologia 24: 231-237.

Matveyenko, A. V., D. Liuwantara, T. Gurlo, D. Kirakossian, C. Dalla Man, C. Cobelli, M. F. White, K. D. Copps, E. Volpi, S. Fujita and P. C. Butler (2012). "Pulsatile portal vein insulin delivery enhances hepatic insulin action and signaling." Diabetes 61: 2269-2279.

Matveyenko, A. V., J. D. Veldhuis and P. C. Butler (2008). "Measurement of pulsatile insulin secretion in the rat: direct sampling from the hepatic portal vein." Am. J. Physiol. 295: E569-E574. 
Meier, J. J., J. D. Veldhuis and P. C. Butler (2005). "Pulsatile insulin secretion dictates systemic insulin delivery by regulating hepatic insulin extraction in humans." Diabetes 54: 1649-1656.

Meissner, H. P. and H. Schmelz (1974). "Membrane potential of beta-cells in pancreatic islets." Pflugers Arch. 351: 195-206.

Merrins, M. J., R. Bertram, A. Sherman and L. S. Satin (2012). "Phosphofructo-2-kinase/fructose2,6-bisphosphatase modulates oscillations of pancreatic islet metabolism." PLoS One 7(4): e34036. Merrins, M. J., B. Fendler, M. Zhang, A. Sherman, R. Bertram and L. S. Satin (2010). "Metabolic oscillations in pancreatic islets depend on the intracellular $\mathrm{Ca}^{2+}$ level but not $\mathrm{Ca}^{2+}$ oscillations." Biophys. J. 99: 76-84.

Nilsson, T., V. Schultz, P.-O. Berggren, B. E. Corkey and K. Tornheim (1996). "Temporal patterns of changes in ATP/ADP ratio, glucose 6-phosphate and cytoplasmic free $\mathrm{Ca}^{2+}$ in glucose-stimulated pancreatic $\beta$-cells." Biochem. J. 314: 91-94.

Nunemaker, C. S., R. Bertram, A. Sherman, K. Tsaneva-Atanasova, C. R. Daniel and L. S. Satin (2006).

"Glucose modulates $\left[\mathrm{Ca}^{2+}\right]$ i oscillations in pancreatic islets via ionic and glycolytic mechanisms." Biophys. J. 91: 2082-2096.

Nunemaker, C. S., M. Zhang, D. H. Wasserman, O. P. McGuinness, A. C. Powers, R. Bertram, A Sherman and L. S. Satin (2005). "Individual mice can be distinguished by the period of their islet calcium oscillations: Is there an intrinsic islet period that is imprinted in vivo?" Diabetes 54: 3517-3522.

Nunemaker, C. S., M. Zhang, D. H. Wasserman, O. P. McGuinness, A. C. Powers, R. Bertram, A. Sherman and L. S. Satin (2005). "Individual mice can be distinguished by the period of their islet calcium oscillations: Is there an intrinsic islet period which is imprinted in vivo?" Diabetes 54: 3517-3522.

O'Rahilly, S., R. C. Turner and D. R. Matthews (1988). "Impaired pulsatile secretion of insulin in relatives of patients with non-insulin-dependent diabetes." N. Engl. J. Med. 318: 1225-1230.

Ortsäter, H., P. Liss, P. E. Lund, K. E. O. Åkerman and P. Bergsten (2000). "Oscillations in oxygen tension and insulin release of individual pancreatic ob/ob mouse islets." Diabetologia 43: 1313-1318.

Polonsky, K. S., B. D. Given, L. J. Hirsch, H. Tillil, E. T. Shapiro, C. Beebe, B. H. Frank, J. A. Galloway and E. van Cauter (1988). "Abnormal patterns of insulin secretion in non-insulin-dependent diabetes mellitus." N. Engl. J. Med. 318: 1231-1239.

Polonsky, K. S., J. Jaspan, D. Emmanouel, K. Holmes and A. R. Moossa (1983). "Differences in the hepatic and renal extraction of insulin and glucagon in the dog: evidence for saturability of insulin metabolism." Acta Endocrinol. (Copenh.) 102: 420-427.

Pørksen, N. (2002). "The in vivo regulation of pulsatile insulin secretion." Diabetologia 45: 3-20.

Pørksen, N., S. Munn, J. Steers, S. Vore, J. Veldhuis and P. Butler (1995). "Pulsatile insulin secretion accounts for $70 \%$ of total insulin secretion during fasting." Am. J. Physiol. 269: E478-E488.

Pørksen, N., B. Nyholm, J. D. Veldhuis, P. C. Butler and O. Schmitz (1997). "In humans at least $75 \%$ of insulin secretion arises from punctuated insulin secretory bursts." Am. J. Physiol. 273: E908-E914.

Ravier, M. A., D. Daro, L. P. Roma, J. C. Jonas, R. Cheng-Xue, F. C. Schuit and P. Gilon (2011).

"Mechanisms of control of the free $\mathrm{Ca}^{2+}$ concentration in the endoplasmic reticulum of mouse pancreatic $\beta$-cells: interplay with cell metabolism and $\left[\mathrm{Ca}^{2+}\right] \mathrm{c}$ and role of SERCA2b and SERCA3." Diabetes 60 : 2533-2545.

Ristow, M., H. Carlqvist, J. Hebinck, M. Vorgerd, W. Krone, A. Pfeiffer, D. Muller-Wieland and C. G. Ostenson (1999). "Deficiency of phosphofructo-1-kinase/muscle subtype in humans is associated with impairment of insulin secretory oscillations." Diabetes 48: 1557-1561.

Ristow, M., M. Vorgerd, M. Möhlig, H. Schatz and A. Pfeiffer (1997). "Deficiency of phosphofructo1-kinase/muscle subtype in humans impairs insulin secretion and causes insulin resistance." $\underline{\mathrm{J}}$. Clin. Invest. 100: 2833-2841.

Ritzel, R. A., J. D. Veldhuis and P. C. Butler (2006). "The mass, but not the frequency, of insulin secretory bursts in isolated human islets is entrained by oscillatory glucose exposure." Am. J. Physiol. 290: E750-E756.

Sakurai, T., J. H. Johnson and K. Uyeda (1996). "Islet fructose 6-phosphate, 2-kinase:fructose 2,6-bisphosphatase: isozymic form, expression, and characterization." Biochem. Biophys. Res. Commun. 218: $159-163$

Santos, R. M., L. M. Rosario, A. Nadal, J. Garcia-Sancho, B. Soria and M. Valdeolmillos (1991).

"Widespread synchronous [ $\left.\mathrm{Ca}^{2+}\right]$ i oscillations due to bursting electrical activity in single pancreatic islets." Pflügers Archiv. 418: 417-422.

Sel'kov, E. E. (1968). "Self-oscillations in glycolysis: a simple kinetic model." European J. Biochem. 4: 79-86.

Sener, A., E. Van Schaftingen, M. Van de Winkel, D. G. Pipeleers, F. Malaisse-Lagae, W. J. Malaisse and H. G. Hers (1984). "Effects of glucose and glucagon on the fructose 2,6-bisphosphate content of pancreatic islets and purified pancreatic B-cells." Biochem. J. 221: 759-764.

Smolen, P. (1995). "A model for glycolytic oscillations based on skeletal muscle phosphofructokinase kinetics." J. theor. Biol. 174: 137-148.

Smolen, P. and J. Keizer (1992). "Slow voltage inactivation of $\mathrm{Ca}^{2+}$ currents and bursting mechanisms for the mouse pancreatic $\beta$-cell." J. Membrane Biol. 127: 9-19.

Song, S. H., S. S. Mclntyre, H. Shah, J. D. Veldhuis, P. C. Hayes and P. C. Butler (2000). "Direct measurement of pulsatile insulin secretion from the portal vein in human subjects." J. Clin. Endocrinol. Metab. 85: 4491-4499.

Stagner, J. I., E. Samols and G. C. Weir (1980). "Sustained oscillations of insulin, glucagon, and somatostatin from the isolated canine pancreas during exposure to a constant glucose concentration." $\mathrm{J}$. Clin. Invest. 65: 939-942.

Tornheim, K. (1979). "Oscillations of the glycolytic pathway and the purine nucleotide cycle." J. theor. Biol. 
79: 491-541.

Tornheim, K. (1997). "Are metabolic oscillations responsible for normal oscillatory insulin secretion?" Diabetes 46: 1375-1380.

Tornheim, K., V. Andrés and V. Schultz (1991). "Modulation by citrate of glycolytic oscillations in skeletal muscle extracts." J. Biol. Chem. 266: 15675-15678.

Tornheim, K. and J. M. Lowenstein (1974). "The purine nucleotide cycle: IV. Interactions with oscillations of the glycolytic pathway in muscle extracts." J. Biol. Chem. 249: 3241-3247.

Valdeolmillos, M., R. M. Santos, D. Contreras, B. Soria and L. M. Rosario (1989). "Glucose-induced oscillations of intracellular $\mathrm{Ca}^{2+}$ concentration resembling electrical activity in single mouse islets of Langerhans." FEBS Lett. 259: 19-23.

Weigle, D. S. (1987). "Pulsatile secretion of fuel-regulatory hormones." Diabetes 36: 764-775.

Westermark, P. O. and A. Lansner (2003). "A model of phosphofructokinase and glycolytic oscillations in the pancreatic $\beta$-cell." Biophys. J. 85: 126-139.

Wierschem, K. and R. Bertram (2004). "Complex bursting in pancreatic islets: A potential glycolytic mechanism." J. theor. Biol. 228: 513-521.

Yaney, G. C., V. Schultz, B. A. Cunningham, G. A. Dunaway, B. E. Corkey and K. Tornheim (1995). "Phosphofructokinase isozymes in pancreatic islets and clonal $\beta$-cells (INS-1)." Diabetes 44: 1285-1289.

Zhan, X., L. Yang, Y. Ming and Y. Jia (2008). "RyR channels and glucose-regulated pancreatic $\beta$-cells." Eur. Biophys. J. 37: 773-782

Zhang, M., P. Goforth, A. Sherman, R. Bertram and L. Satin (2003). "The $\mathrm{Ca}^{2+}$ dynamics of isolated mouse $\beta$-cells and islets: Implications for mathematical models." Biophys. J. 84: 2852-2870. 